\title{
Correction to: Glaciimonas soli sp. nov., a soil bacterium isolated from the forest of a high elevation mountain
}

\author{
Wei-Sheng Huang $\cdot$ Li-Ting Wang $\cdot$ Jun-Ning Sun • Jwo-Sheng Chen • \\ Ssu-Po Huang $\cdot$ Shih-Ting Lin • Lina Huang • Wung Yang Shieh
}

Published online: 4 January 2021

(C) Springer Nature Switzerland AG 2021

\section{Correction to:}

Antonie van Leeuwenhoek (2020) 113:1213-1223

https://doi.org/10.1007/s10482-020-01428-z

In the original publication of the article, in the abstract, the JCM number of the strain Glaciimonas soli was incorrectly published as: $\mathrm{GS}^{\mathrm{T}}\left(=\mathrm{JCM} 33275^{\mathrm{T}-}\right.$ $=$ BCRC $81091^{\mathrm{T}}$ ).

However, the correct JCM number is 32375 .

Publisher's Note Springer Nature remains neutral with regard to jurisdictional claims in published maps and institutional affiliations.

The original article can be found online at https:// doi.org/10.1007/s10482-020-01428-z.

W.-S. Huang · J.-N. Sun · S.-P. Huang

W. Y. Shieh $(\square)$

Institute of Oceanography, National Taiwan University, PO Box 23-13, Taipei 10617, Taiwan

e-mail: winyang@ntu.edu.tw

L.-T. Wang $\cdot$ S.-T. Lin $\cdot$ L. Huang

Bioresource Collection and Research Center, Food

Industry Research and Development Institute, 331 Shih-

Pin Rd., Hsinchu 30062, Taiwan

\section{J.-S. Chen}

College of Health Care, China Medical University, No.

91, Shyue-Shyh Rd, Taichung, Taiwan 